\title{
Apontamentos sobre o testemunho infantil na historiografia da Educação (Brasil, Séculos 19 e 20) ${ }^{1}$
}

Notes about the testimony of children in the historiography of Education (Brazil, $19^{\text {th }}$ and $20^{\text {th }}$ centuries)

Apuntes sobre el testimonio infantil en la historiografía de la Educación (Brasil, Séculos 19 y 20)

\author{
Juarez José Tuchinski dos Anjos \\ Universidade de Brasília (Brasil) \\ https://orcid.org/0000-0003-4677-5816 \\ http://lattes.cnpq.br/7560916850762011 \\ juarezdosanjos@yahoo.com.br
}

\section{Resumo}

Em se tratando de tentar ouvir a voz da criança do passado, a que tipos de testemunhos infantis têm recorrido os historiadores e historiadoras da educação brasileira? Oferecer alguns apontamentos em torno dessa questão é o objetivo deste artigo. O recorte cronológico adotado transita entre os séculos 20 e 19. Em termos metodológicos, visita três campos historiográficos, entre os quais há intersecção e cruzamento de interesses em torno da criança no passado: o da historiografia da infância, o da historiografia da cultura sobre o Brasil e o da historiografia da educação propriamente dita. As conclusões apontam que, a depender do período estudado, variam as fontes disponíveis. Para o século 20 têm sido utilizadas, recentemente, escritas infantis, documentos produzidos pela própria criança (cadernos escolares ou correspondências). Já para o século 19, os egodocumentos são as fontes que, mesmo indiretas, permitem acessar as experiências da criança brasileira daquela época.

Palavras-chave: Fontes. Infância. História da Educação. Historiografia.

\footnotetext{
${ }^{1}$ Este artigo apresenta resultados parciais de uma pesquisa de pós-doutoramento financiada pelo PNPDCAPES, agência de fomento à qual registro meus agradecimentos.
} 


\begin{abstract}
Regarding attempts to listen to the voice of children of the past, what types of testimonies by children have the historians of the Brazilian education been investigating? This paper aims at offering some notes regarding this theme. Chronologically, it focuses on the $19^{\text {th }}$ and $20^{\text {th }}$ centuries. In methodological terms, it approaches three historiographical fields presenting intersection of interests in relation to children of the past: historiography of childhood, historiography of culture about Brazil, and historiography of education. The conclusions pointed out that the available sources vary according to the studied period. For the $20^{\text {th }}$ century, writings and documents produced by children have been used (school notebooks or correspondences). In turn, for the $19^{\text {th }}$ century, egodocuments are the sources that, despite being indirect, allow access to the experiences of Brazilian children of that time.
\end{abstract}

Key words: Sources. Childhood. History of Education. Historiography.

\title{
Resumen
}

En cuanto a tratar de oír la voz del niño del pasado, ¿a qué tipos de testimonios infantiles han recurrido a los historiadores e historiadoras de la educación brasileña? Ofrecer algunos apuntes en torno a esta cuestión es el objetivo de este artículo. El recorte cronológico adoptado transita entre los siglos 20 y 19. En términos metodológicos, visita tres campos historiográficos, entre los cuales hay intersección y cruce de intereses en torno al niño en el pasado: el de la historiografía de la infancia, el de la historiografía de la cultura sobre el Brasil y el de la historiografía de la educación propiamente dicha. Las conclusiones apuntan que, dependiendo del período estudiado, varían las fuentes disponibles. Para el siglo XX se han utilizado recientemente escrituras infantiles, documentos producidos por el propio niño (cuadernos escolares o correspondencia). Ya para el siglo 19, los egodocumentos son las fuentes que, incluso indirectas, permiten acceder a las experiencias del niño brasileño de aquella época.

Palabras clave: Fuentes. Infancia. Historia de la Educación. Historiografía. 
Ao refletir sobre a operação historiográfica, Michel de Certeau afirmou que "em História, tudo começa com o gesto de separar, de reunir, de transformar em 'documentos' certos objetos distribuídos de outra maneira" (CERTEAU, 2002, p. 81). O exercício epistemológico da escrita da História impõe que o historiador procure se aproximar dos seres humanos do passado por meio dos vestígios, ora diretos, ora indiretos, que nos tenham legado de suas existências. É através dessa mediação, esclarece Robert Darnton, que o pesquisador consegue "... conversar com os mortos" já que "fazendo perguntas aos documentos e prestando atenção às respostas, pode-se ter o privilégio de auscultar almas mortas e avaliar as sociedades por elas habitadas" (DARNTON, 1987, p. 7).

Mas, em se tratando de tentar ouvir a voz da criança do passado, particularmente na condição de aluno das escolas primárias, mas também em outros aspectos da vida infantil, a que tipos de testemunhos infantis têm recorrido os historiadores e historiadoras da educação brasileira? Oferecer alguns apontamentos em torno dessa questão é o objetivo deste artigo.

Por testemunho infantil estou entendo, aqui, aqueles documentos produzidos pelas próprias crianças, no tempo da infância; ou produzidos por adultos rememorando experiências vivenciadas nas suas infâncias, nos quais é possível, ainda que de modo indireto, por meio de uma retórica da infância (BECCHI, 1994), deixar que a criança do passado fale pelas mãos de um "outro", isto é, o adulto que ela se tornou. O recorte cronológico adotado aqui transita, diacronicamente ainda que de forma pontual e verticalizada, entre pesquisas que abarcaram o século 20 (tradicionalmente mais visitado pela historiografia) e o século 19, particularmente o período imperial que, cada vez mais, tem atraído o interesse dos estudiosos do nosso passado educacional.

Em termos metodológicos e para uma análise mais matizada da problemática deste artigo - que não é preocupação exclusiva dos historiadores da educação - a visita a ao menos três campos historiográficos, entre os quais há intersecção e cruzamento de interesses em torno da criança e das infâncias no passado, tornou-se incontornável: o da historiografia da infância, o da historiografia da cultura sobre o Brasil e o da historiografia da educação propriamente dita.

No caso da historiografia da infância, apesar do interesse deste artigo ser o de apreender testemunhos infantis em nível de Brasil, foi preciso dialogar, em determinados momentos, também com a historiografia internacional, sobretudo, para evidenciar melhor algumas escolhas que, dada a natureza dos arquivos e da empiria disponível em nosso país, esclarecem as especificidades do modo como cá, deste lado do oceano e abaixo da linha do Equador, historiadores e historiadoras tem enfrentado o desafio de produzir fontes nas quais se possa apreender a voz da criança do passado.

Já a historiografia da cultura, embora representada somente por uma obra, da lavra de Gilberto Freyre, diz respeito à produção de um autor cujas explicações sobre a meninice tiveram notável influência no campo da história da cultura e da história da infância no Brasil, como demonstram, entre outras, as análises de Peter Burke (2002) e Amurabi Oliveira (2015).

A historiografia da educação selecionada, por sua vez, diz respeito a trabalhos recentes, produzidos nos últimos 15 anos e que, sem a pretensão de revisão ou análise exaustiva da produção, parecem constituir, não obstante, uma amostra reveladora e pontual de como a questão do testemunho infantil têm comparecido na pesquisa histórico educacional tanto sobre o século 20 como, em especial, o século 19, com ênfase no período imperial. 
Quando, em 1960, Philippe Ariès publicava L'enfant e la vie familiale sous l'Ancièn Regime, inaugurava, hoje o sabemos, um novo canteiro da pesquisa histórica, a história da infância ${ }^{2}$. Desde então, cresceu muito o interesse dos historiadores e historiadoras por compreender como era o ser criança em outras épocas. Acerca disso, escreve Angela Giallongo:

A história da infância não é mais negligenciada pela comunidade intelectual do nosso tempo. O confirma a sua difusão na literatura internacional e a proliferação dos estudos nas universidades estadunidenses e sul-americanas, nos países do Oeste, do Médio Oriente e europeus [...]. Nestes últimos decênios se desenvolveu de tal modo que começa a afirmar-se como aspecto consciente e todo particular no estudo do passado humano (GIALLONGO, 2002, p. 8, tradução livre).

No Brasil, desde a publicação das obras coletivas organizadas por Mary Del Priore (1991; 1999), começou a constituir-se, de modo mais evidente, uma historiografia da infância, na interface com a história da assistência e proteção à criança (MARCÍLIO, 1998; RIZZINI, 2000) e, mais recentemente, da educação (SOUZA, 2010; FARIA FILHO e ARAÚJO, 2011). No restante da América Latina, igualmente, os estudos históricos sobre a infância conheceram amplo desenvolvimento em praticamente todos os países (JÍMENEZ; MANARELLI, 2007; SOSENSKI; ALBARRÁN, 2012). No âmbito europeu e norteamericano, obras como as organizadas por Egle Becchi e Dominique Julia (1998) e Paula Fass (2003) ou de síntese historiográfica, como as escritas por Hugh Cunninghan (1997), Colin Heywood (2004) e Peter Stearns (2006) também confirmam o vigor e diversidade da produção historiográfica sobre a temática.

Se o interesse dos historiadores pelo campo tem se generalizado, os enfoques são bastante variados. Isso se explica, em parte, pela diversidade teórica da produção - enquanto que na Itália, por exemplo, há uma permanente preocupação teórico-conceitual com a escrita da história da infância (cf. BECCHI, 2010; BECCHI e JULIA, 1998) no Brasil, só esporadicamente se discutem tais aspectos (cf. WARDE, 2007; GOUVÊA 2009) - mas, sobretudo, pela natureza da empiria disponível.

No conjunto do que denominamos "História da Infância", há duas dimensões que, no plano da experiência histórica, são indissociáveis: a história da infância (isto é, a história do tempo social da vida humana construído na relação entre as gerações e que se modifica em cada contexto histórico e social) e a história da criança (que seria a história dos sujeitos sociais desse tempo da vida humana e do modo como se relacionaram com os adultos e/ou entre si e ajudaram a produzir suas próprias infâncias). O ideal seria que essas duas dimensões pudessem ser sempre estudadas articuladamente na historiografia da infância; todavia, por razões empíricas, é geralmente em uma ou outra direção que a pesquisa tem se consolidado, quando analisamos a historiografia em âmbito transnacional.

Em países como Estados Unidos, Inglaterra e Holanda, onde se dispõem de fontes produzidas por crianças, como diários infantis (POLLOCK 2004; DEKKER, 1999; LEJEUNE, 1995); ou como a Itália, onde arquivos renascentistas abrigam cartas e correspondências das crianças das famílias de elite ducal (FERRARI et al, 2010); ou museus escolares custodiam cadernos com escritas infantis (MEDA, MONTINO, SANI, 2010), a historiografia tendeu a se beneficiar, conseguindo com frequência, ouvir a voz da criança do passado, escrevendo uma história, não raro, em primeira pessoa, uma história da criança. Já em países como Brasil, onde

2 No Brasil, publicado em versão reduzida, sob o título: "História social da criança e da família" (ARIÈS, 1978). 
registros escritos por crianças são bastante escassos e, mesmo quando existentes, de difícil acesso, os historiadores tem se valido, sobretudo, de registros dos adultos sobre as crianças, como correspondências familiares, relatos de viajantes, processos crimes, relatórios de professores, etc., resultando, assim, em escritas históricas eminentemente sobre a infância.

De alguns anos para cá, entretanto, esse enfoque tem se modificado lentamente no Brasil, sobretudo, pelas contribuições vindas da labuta de algumas historiadoras e sua inventividade na busca e localização de novas fontes, mesmo que, muitas vezes, o interesse imediato não seja o de uma história da infância/ da criança, mas, antes, da educação ou de outros aspectos ligados aos pequenos e seus processos de socialização no século 20. Os trabalhos que recorrem a essa base empírica ainda são raros. Neles dois tipos de fontes se destacam: cadernos escolares e correspondências infantis.

Na primeira direção, Eliane Peres (2017), em estudo há pouco publicado, se propõe a investigar escritas de alunos do que hoje denominamos anos iniciais da educação básica, relativos a viagens familiares e passeios escolares realizados, registrados em cadernos de escola existentes no acervo do HISALES, na Universidade Federal de Pelotas. Nas conclusões, propondo dois questionamentos em particular - "sob qual perspectiva as crianças, alunos e alunas da fase inicial da escolarização, registram suas experiências familiares de viagens e passeios? [...] o que os textos das crianças permitem apreender sobre viagens e passeios no espaço escolar?" (PERES, 2017, p. 306) - destaca que:

Em relação ao primeiro questionamento pode-se concluir que, no universo pesquisado, os textos das crianças indicaram aspectos como: os limites culturais e geográficos de seus passeios e viagens; a relação com familiares e amigos, aparentemente reforçadas em períodos de férias, em muitos casos em espaços rurais; a coexistência de um tempo de colaborar com os pais em pequenas tarefas domésticas, de estudar e brincar, ainda, de algumas tradicionais brincadeiras infantis, com indícios de separação de gênero no que tange a essas brincadeiras e brinquedos. Há, notadamente, uma diferença nos textos produzidos pelos alunos e alunas, quando escrevem sobre suas férias, passeios e viagens familiares e quando o fazem em referência a essas atividades realizadas no âmbito escolar. No primeiro caso, há uma escrita "mais livre", aparentemente menos controlada e menos corrigida, diferente daquela que registra passeios e viagens escolares. Assim, em relação à segunda pergunta, pode-se enfatizar que poucos são os passeios ou viagens escolares registrados nos cadernos que revelam uma dimensão mais lúdica ou "passeio-repouso", como denominou Sampaio (1994, p. 81), em referência à aula passeio da pedagogia Freinet. O que os dados indicaram é a existência, na escola, de "passeios-formação" (SAMPAIO, 1994, p. 181), quais sejam, aqueles feitos especificamente para aprender ou reforçar um conteúdo escolar (vegetais, bichos, meio ambiente, sistema monetário, períodos e fatos históricos, como nos exemplos mostrados). Além disso, pelos textos, é possível perceber que passeios e viagens escolares são feitos, na maioria das vezes, a lugares associados a uma "cultura legítima": museus, bibliotecas, cinema, casarões históricos. Nesse sentido, revelam também uma perspectiva de história, de memória e de cultura que a escola preserva e, inclusive, contribui para sua construção (PERES, 2017, p. 306-307). 
$\mathrm{Na}$ segunda direção empírica, da indagação de produções infantis contidas em correspondências, o estudo também publicado recentemente por Luciana Santos e Maria Teresa Santos Cunha (2017), é bastante significativo. Nele, as historiadoras investigam cartas enviadas por crianças leitoras ao suplemento infantil dominical do jornal $O$ Estado, que circulou em Santa Catarina entre 1972 e 1987, concluindo que

A seção de cartas, existente desde os primeiros anos do suplemento, permitiu compreender como foram se estreitando as relações entre o suplemento e seus leitores, sobretudo, a partir de 1984. O Estadinho passou a incentivar a participação de seus leitores em várias seções do suplemento, criando cada vez mais espaços para a publicação de desenhos, reportagens, poesias e até mesmo receitas.

As cartas trocadas na coluna "cartas" evidenciaram tais participações, pois por meio delas, meninas, meninos, mesmo que incentivados por adultos, expunham seus desejos e intenções naquele ato de escrita. As cartas continham palavras de carinho e em sua maioria solicitavam a publicação de algum texto, desenho, ou mesmo uma receita culinária. Respondidas e publicadas, respondiam o tom amistoso e a promessa de publicação, que por vezes dizia ao leitor que havia necessidade de esperar (SANTOS; CUNHA, 2017, p. 251).

Em operação historiográfica semelhante, vale destacar o trabalho de Patrícia Tavares Raffaini (2015), que se debruçou sobre cartas enviadas por crianças leitoras, nas décadas de 30 e 40, aos escritores Monteiro Lobato, no Brasil e Laura Ingalls Wilder, nos Estados Unidos. Numa análise comparativa entre as experiências leitoras dessas crianças, manifestas aos seus autores prediletos por meio de cartas, a historiadora aponta que

Nas cartas aqui analisadas as crianças se mostram como seres completos, exercem o papel de correspondente, pois já sabem utilizar a linguagem escrita e os modelos epistolográficos, mas ao mesmo tempo se permitem algumas "liberdades", pois se desculpam pela letra, os borrões ou a escrita a lápis. Ao utilizarem formas pessoais de tratamento, não estão sendo ingênuas, mas sim utilizando um recurso para se tornarem próximas daqueles que admiram. A documentação também nos revela que as práticas de leitura eram similares nos dois países, muitas crianças relatam ler de forma intensiva, não por não terem acesso a outros livros, mas pelo prazer de reler uma obra querida. Assim também a prática de leitura coletiva, em família, é relatada pelas crianças daqui e de lá. Durante o período aqui analisado o acesso aos livros era difícil para a maioria das crianças brasileiras leitoras, em virtude principalmente do alto custo dos livros infantis e da inexistência de bibliotecas públicas com acervos voltados para a infância. Apesar disso, as cartas nos mostram que ao ter acesso ais livros as crianças brasileiras realizavam a leitura de maneira análoga ao público norte-americano, que contava com uma rede de bibliotecas consolidada. A leitura para os leitores de ambos os países que se corresponderam com seus escritores favoritos era fonte de prazer, de divertimento e de deleite. Pelo que as cartas nos revelam tanto 
Lobato quanto Laura parecem ter alcançado o que pretendiam com sua produção literária (RAFFAINI, 2015, p. 157).

Parece plausível supor que, nos próximos anos, se investimentos historiográficos como estes continuarem a ser feitos, outros estudos enfocando o testemunho direto da criança possam vir a lume, contribuindo, assim, para o avanço da historiografia da infância e da educação enquanto história de meninos e meninas, no século 20. Realmente, a julgar pelo estado atual dos arquivos, é de se imaginar que se consigam, ainda, garimpar evidências e fontes de autoria infantil desde que se sensibilizem as instituições de guarda sobre a importância desse patrimônio de produções dos pequenos como inestimáveis documentos sociais para a compreensão do mundo em que vivemos, tanto ontem como hoje. Da mesma forma, se conscientizem os adultos - a começar por nós mesmos! - para que, nas suas relações com as crianças, valorizem os registros que estas produzem e preservem-nos a fim de garantir sua sobrevivência para futuras pesquisas/investigações.

Contudo, para o século 19 brasileiro, salvo alguma grande descoberta arquivística que se venha a fazer (o que, em se tratando de pesquisa histórica, é imponderável), a existência de testemunhos infantis é muito mais incomum e escassa. Logicamente, como aguça Lucien Febvre (1989), cada historiador aprende a fabricar seu mel a partir das fontes de que dispõe ou a fazer flecha com qualquer madeira, na expressão provocadora de Dominique Julia (2001). Um corpus documental de onde um pouco desse mel pode ser extraído ou alguma boa madeira obtida, no caso do nosso Oitocentos nos Trópicos, parece ser o constituído pelos registros egodocumentais de pessoas que nasceram no século 19 e que oferecem testemunhos sobre sua infância e suas experiências infantis.

\section{3.}

Por egodocumentos podemos definir, com Antonio Viñao, "aqueles textos nos quais o sujeito fala ou se refere a si mesmo, nos quais o eu encontra refúgio e se converte em elemento de referência" (VIÑAO, 2000, p. 11, tradução livre). Esse tipo de documentos, porém, abrange uma diversidade de gêneros textuais, como diários, memórias, reminiscências, autobiografias, etc. Em via de regra, para o caso brasileiro e no que diz respeito ao seu potencial como testemunhos da infância, são geralmente relatos memorialísticos nos quais um adulto rememora sua infância, permitindo, assim, que se obtenham informações, ainda que indiretas e mediadas pelos emaranhados fios da memória, sobre a criança que um dia foi.

Um pioneiro na tentativa escutar a voz da criança do passado através do adulto que ela se tornou, entre nós, foi, sem dúvida, Gilberto Freyre. Deveras conhecido, reconhecido e criticado por sua obra mestra Casa Grande \& Senzala, pouco espaço tem havido entre seus afetos e desafetos intelectuais para a discussão do livro que fecha a trilogia que sua opus magna inaugurou. Na realidade, Freyre planejava escrever uma quadrilogia sobre a formação da sociedade brasileira. Das quatro obras previstas, redigiu três. À Casa Grande e Senzala (publicada em 1933) seguiram-se Sobrados e Mucambos (1936) e Ordem e Progresso (1957) ${ }^{3}$. A meu ver, é este último o mais inventivo de todos. Nele, Freyre adotou um método bastante inovador para os anos 1950, imaginado e colocado em prática, porém, desde uns vinte anos antes e que consistiu no

\footnotetext{
${ }^{3}$ O quarto livro seria "Jazigos e Covas Rasas", que jamais chegou a ser escrito, embora seu plano tenha sido exposto pelo próprio Freyre no Prefácio da $1^{\mathrm{a}}$ edição de Ordem e Progresso.
} 
estudo de considerável número de autobiografias de indivíduos nascidos em nosso país entre 1850 e 1900: indivíduos dos dois sexos, das três raças e de suas várias nuances de mestiçagens; de profissões diversas, de condições sociais e intelectuais diferentes; de credos ou fé também diferentes. Essas autobiografias, dificílimas de recolher, foram provocadas. Mais do que isso: foram dirigidas. Dirigidas porque solicitou-se de cada autobiografado que, embora podendo-se expandir livremente naquelas reminiscências que fossem mais do seu gosto e do seu agrado ou que the viessem espontaneamente à lembrança, respondesse a determinadas perguntas. Tais perguntas foram feitas a mais de mil brasileiros nascidos àquela época com o fim de se conseguirem deles reações aos mesmos estímulos, informações sobre os mesmos assuntos, possíveis revelações de diferentes traumas ou euforias suscitados pelos mesmos acontecimentos com repercussões diversas sobre indivíduos da mesma época e do mesmo país. Não obtivemos mil respostas escritas ao questionário organizado com a intenção de provocar essas autobiografias dirigidas (...). Mesmo assim, chegaram a quase trezentas as respostas escritas e conseguidas durante anos de paciente colheita (...) (FREYRE, 2010, p. 18).

Tão inovador quanto a proposta de obter autobiografias provocadas, é o questionário que cada depoente foi solicitado a tomar como guia para a evocação de suas reminiscências. Algumas das perguntas feitas pelo sociólogo, ainda hoje, encontram-se nas indagações de boa parte dos historiadores da infância e da educação. Antes de nós, porém, Freyre as fez:

1. Nome

2. Lugar onde nasceu (com descrição do mesmo lugar no tempo da meninice)

3. Escola ou colégio que frequentou (métodos, professores, colegas, castigos, brinquedos, jogos, trotes, livros escolares, estudo de gramática, de caligrafia, de matemática, festas cívicas, etc.).

4. Brinquedos, camaradagens, jogos e leituras de menino fora da escola;

5. Quais os seus heróis do tempo de menino? Quem queria ser quando fosse grande? Que mais ardentemente queria ser?

6. Por que se fixou na profissão que veio a seguir? Onde fez os estudos profissionais? Professores, escolas e leituras desse período?

7. Qual a sua impressão da República ao tempo da meninice e adolescência?

8. Qual a sua impressão de Santos Dumont ao tempo da sua mocidade e quando esteve no auge da glória?

9. Qual a sua atitude de menino, de jovem, de homem-feito para com a) Paris; b) Europa; c) Igreja Católica; d) Positivismo; e) Darwin; f) os chamados Direitos da Mulher? g) O divórcio; h) o clero; i) o ensino no Brasil (primário, profissional, etc.); k) Rui Barbosa em Haia; 1) Rio Branco (O Barão); m) Nietzsche; n) Karl Marx; o) A. Comte; p) Spencer;

10. Quais danças ou modinhas de sua predileção no tempo de rapaz (ou de mocinha)?

11. Frequentava café ou confeitaria? Restaurante ou Hotel? Clube? 
12. Seus alfaiates ou modistas? Suas preferências de modas (inglesas, francesas, americanas)? Suas preferências em chapéus, calçados, roupas de dentro, guarda-chuvas, bengala, joias?

13. Quais os jornais e revistas brasileiros e estrangeiros, da sua preferência, do tempo de jovem?

14 Viagens que fez quando moço, no Brasil ou no estrangeiro?

15. Suas ideias de rapaz, de reforma social, em geral, de reforma social e política no Brasil, em particular?

16 a - Sua atitude para com negros, mulatos e pessoas de cor?

$16 \mathrm{~b}$ - Como receberia o casamento de filho ou filha, irmão ou irmã, com pessoas de cor? De cor mais escura que a sua?

17. Outras reminiscências (FREYRE, 2010, p. 27).

Como se nota a partir deste questionário, o objetivo era compreender como se deu o processo de transição do Império para a República por meio da análise das mudanças que teriam ocorrido na vida social, material, intelectual e cultural do país, a partir das percepções de seus entrevistados, especialmente, no tempo da infância. Destaca-se, por exemplo, o fascínio que os soldados e oficiais da guerra do Paraguai exerciam sobre os meninos durante a idade pueril, povoando seu imaginário e brincadeiras, meninos que, em 1889, já rapazes, assistiram ao golpe republicano liderado por setores militares com sentimentos contraditórios, entre admiração pelo que faziam seus heróis da meninice e o receio pelas transformações que isso por vezes acarretava, inclusive, na vida de suas famílias.

Freyre observou, também, como as mudanças na transição da edu cação imperial para a republicana foram lentas e práticas costumeiras, como os castigos físicos, se mantiveram por muito tempo na escolarização das gerações mais jovens. São sobre a educação, por sinal, as páginas mais interessantes de Ordem e Progresso. Através dos depoimentos de seus entrevistados, acompanha o nascimento da influência americana na educação, com os colégios protestantes; a emergência do recreio nas escolas, o currículo prescrito e o ensinado, os métodos adotados no ensino da leitura e da escrita; os livros de leitura que mais marcaram a infância das crianças tanto na escola como fora dela. Temas, como se vê, ainda caros à historiografia da educação contemporânea.

Entretanto, se o estudo de Gilberto Freyre ia do Império à República, é, sobretudo, entre historiadores e historiadoras do segundo período que vamos encontrar, atualmente, a maior parte das pesquisas que, ainda que por caminhos independentes, perseguem parte das pistas lançadas pelo sociólogo brasileiro antes mesmo do nascimento da História da Infância (razão, pela qual, Peter Burke (2002) já chegou a considerá-lo, de certa maneira, um dos seus precursores).

Nesse sentido, encontram-se e são relativamente bem conhecidos os estudos sobre a escrita egodocumental da jovem Helena Morley (pseudônimo de Ana Caldeira Brandt) na Diamantina de fin de siècle (FREITAS; CUNHA 2001; Aguiar, 2004;), da pequena Cora Coralina (pseudônimo de Anna Lins dos Guimarães Peixoto Bretas) na escola da mestra Silvina e nas suas vivências pelos becos e ruas da Goiás da primeira década republicana (VALDEZ, 2011; PERES; BORGES 2015) ou de José Lins do Rego e outros memorialistas paraibanos, tão bem interrogados e analisados por Ana Maria de Oliveira Galvão (1998).

Já em se tratando do período imperial, rareiam investigações que tenham privilegiado como fonte principal egodocumentos e as evidências da infância e da escolarização que eles contêm. Fazendo uma busca por trabalhos que se propusessem a interpretar a história da educação imperial a partir dessa empiria - ainda que sem a pretensão de levantamento exaustivo, mas contemplando o principal evento da área; os cinco periódicos de História da Educação em circulação no Brasil atualmente; o conjunto de periódicos disponíveis em uma 
das mais importantes bases de consulta (o SCIELO); os anais e a revista da Sociedade Brasileira de Pesquisa (Auto) Biográfica ${ }^{4}$ - localizei, apenas, três pesquisas enquadradas nesse critério.

$\mathrm{Na}$ primeira delas, Ana Cristina Pereira Lage (2006), através do registro memorialístico de Francisco de Paula Ferreira Rezende, nascido em 1832 na cidade mineira de Campanha, discute alguns aspectos da história da educação campanhense, tomando as experiências de escolarização vividas por ele na infância como fio condutor da narrativa e interpretação históricas, cruzando-a, quando necessário, com fontes de caráter oficial. Assim munida, analisa o tipo de escola pública primária que ele frequentou, regida segundo o método mútuo; a prática de castigos físicos adotada pelo mestre (contrariando, assim, um dos pressupostos do método de Lancaster, que era a adoção de castigos morais ao invés das punições corporais); as relações interpessoais do memorialista com o professor, que parecem ter lhe tornado menos penosa a escolarização (sendo castigado apenas duas vezes e tendo a permissão para brincar com um colega no quintal da casa do mestre além de poder provar alguns quitutes feitos pela esposa do docente); a organização da escola em classes (nas quais, segundo percepção do egoautor, o professor tendia a desprezar as mais inferiores) e, também, aspectos materiais, como a adoção da caixa de madeira com areia para o ensino da escrita, considerada pelo memorialista uma novidade para aquele contexto.

O segundo estudo encontrado é da lavra de Névio Campos (2011). Nele, o historiador se propõe a analisar a trajetória escolar, na perspectiva da história intelectual, do paranaense Victor Ferreira do Amaral e Silva, nascido na Lapa, em 1862, valendo-se, primordialmente, de sua autobiografia intitulada "Minha infância escolar". Em função das informações presentes no registro memorialístico interrogado, que enfatiza mais o ensino secundário, iniciado em Curitiba e concluído no Rio de Janeiro, do que o ensino primário, realizado no Paraná, são poucas as interpretações que pode construir sobre a experiência escolarização elementar do memorialista. Entretanto, destaca que teria iniciado sua instrução na cidade natal, dando prosseguimento a ela em um colégio particular, evidenciando, assim, os múltiplos espaços em que a educação escolar se dava no momento mesmo da institucionalização da escola entre nós, no Brasil Império. Nas conclusões, observa que essa peregrinação escolar, no caso de Victor Ferreira do Amaral, tinha objetivos bastante claros para as elites locais, das quais ele era um membro:

por meio da trajetória de Victor Ferreira do Amaral foi possível compreender o movimento da elite política e econômica da Província do Paraná ao longo da segunda metade do século XIX que visava por seus filhos nas escolas de prestígio, preparando-os para ingressar no ensino superior e garantir suas presenças nos espaços públicos e privados de maior relevo no cenário paranaense (CAMPOS, 2011, p.84).

Por fim, a terceira pesquisa encontrada é a desenvolvida por Nayana Rodrigues Cordeiro Mariano (2017). O objetivo do trabalho foi o de "a partir das memórias de Coriolano de Medeiros [...] discutir a instrução pública e particular nas últimas décadas do século XIX, na então Província da Paraíba do Norte" (MARIANO, 2017, p. 1). A fonte privilegiada foi o texto

\footnotetext{
${ }^{4}$ Refiro-me aos Congressos Brasileiros de História da Educação (2000-2017), Revista História da Educação ASPHE (1997-2017); Revista Hisdtebr-online (2009-2017); Revista Brasileira de História da Educação (20012017); Cadernos de História da Educação (2002-2017) e Revista de História e Historiografia da Educação (2017); Periódicos disponíveis na base Scielo (1997-2017);Anais dos Congressos Internacionais de Pesquisa (Auto) Biográfica (2004-2016) e a Revista Brasileira de Pesquisa (Auto)Biográfica (2016-2017). Para esclarecimento do leitor, as datas entre parênteses referem-se à cronologia consultada em cada uma das bases, de acordo com o que pude encontrar disponível on-line. Para as edições do CBHE consultaram-se os anais na íntegra; do CIPA os anais ou resumos (quando disponíveis) ao passo que nos periódicos a pesquisa foi feita, no modo livre, com as palavraschave no singular e plural: autobiografia(s), memória(s).
} 
memorialístico $O$ Tambiá de minha infância, no qual Coriolano de Medeiros, nascido em 1875 na Província da Paraíba, relata suas reminiscências escolares na capital provincial, a atual João Pessoa e, à época, Paraíba do Norte. No que diz respeito à instrução primária, a historiadora, cruzando autobiografia com outras fontes, como jornais, aponta as diversas experiências de escolarização vividas pelo menino Coriolano na década de 1880: a escola mista da professora Cecília Cordeiro, onde aprendeu as primeiras letras e realizou a leitura do primeiro livro do Barão de Macaúbas; a segunda escola, onde conheceu o rigor e o desconforto da jornada escolar, já que a aula funcionava "de nove da manhã às quatro e meia da tarde, com o odor do lixo sempre rondando o ambiente, o cansaço pelo horário de estudos e a presença constante da palmatória" (MARIANO, 2017, p. 4) e a terceira e última escola de primeiras letras, também funcionando em espaço insalubre e impróprio para a saúde infantil.

\section{4.}

Para concluir, pode-se afirmar que, a depender do período histórico estudado - século 20, fim do século 19 ou período imperial - variam as fontes disponíveis e, com isso, os testemunhos infantis a que têm recorrido os historiadores e historiadoras da educação no Brasil na busca por escutar a voz da criança no passado e a conferir-lhe maior centralidade na construção de explicações históricas sobre o período da vida humana a que chamamos infância.

Identificamos que, para o século 20 têm sido utilizadas, recentemente, escritas infantis, documentos produzidos pela própria criança (ainda que não se possa perder de vista a eterna influência que sobre esse tipo de material os adultos sempre terão, seja orientando sua produção ou, mesmo, selecionando o que veio a ser preservado), materializados em cadernos escolares ou correspondências. Já para o século 19, os egodocumentos - embora não se possa afirmá-los categoricamente como os únicos documentos disponíveis, mas, certamente, os que têm sido efetivamente utilizados para contornar a ausência de fontes contemporâneas de autoria infantil - parecem ser a empiria que, mesmo indireta, permite chegar bem perto do cotidiano e das experiências históricas da criança brasileira daquela época, sobretudo, evidenciando a perspectiva a partir da qual participaram dos processos ligados à sua educação e socialização.

Para além dos apontamentos que este artigo buscou oferecer sobre a questão, cabe registrar, ainda, a necessidade tanto de investimentos na localização de novos documentos infantis para o século 20, enquanto podem ser identificados e preservados bem como no levantamento e sistematização de egodocumentos relativos às infâncias vivenciadas no século 19 brasileiro, como base para novas pesquisas que procurem privilegiar a criança como ator histórico, mesmo quando sua voz só possa ser capturada de forma indireta pela pena do adulto que ela se tornou. De fato, é também papel do historiador ajudar a sociedade da qual faz parte a desenvolver a consciência histórica sobre a importância da criança na vida coletiva, tanto no passado que ele estuda como no presente que ele vive. O cuidado com os registros infantis e o investimento em pesquisas que deem protagonismo a essas vozes - especialmente em períodos menos estudados ou onde essa presença é mais difícil de ser evidenciada - é uma das formas de exercício da escuta, respeito e atenção que se pode dar à criança partícipe da história.

\section{Referências}

AGUIAR, Maria Salete Alves de. Imagens de um processo formativo: a educação da menina no diário "Minha Vida de Menina" de Helena Morley (Mestrado em Educação). Faculdade de Educação da Universidade Estadual de Campinas. Campinas, 2004.

ARIÈS, Philippe. História social da criança e da família. Rio de Janeiro: Zahar, 1978. 
BECCHI, Egle. I bambini nella Storia. Roma-Bari: Laterza, 2010.

BECCHI, Egle. Retórica de Infância. Perspectiva. Florianópolis, n. 22, p. 63-95, ago. - dez., 1994.

BECCHI, Egle; JULIA, Dominique (sur la dir.) Histoire de l'Enfance en Occidente. 2 Tomes. Paris: Seuil, 1998.

BURKE, Peter. O pai do homem: Gilberto Freyre e a história da infância. In: FREYRE, Gilberto. Casa Grande e Senzala: edição crítica. Madri/São Paulo: ALLCA XX, 2002, p.786-796.

CAMPOS, Névio. Victor Ferreira do Amaral e Silva: do oikos a scholé (1862-1878). Revista Histedbr-online. Campinas, v. 41, 2011, p. 72-87. DOI: https://doi.org/10.20396/rho.v11i41.8639836.

CERTEAU, Michel de. A Escrita da História. Rio de Janeiro: Forense Universitária, 2002.

CUNNINGHAM, Hugh. Storia dell'Infanzia. XVI-XX secolo. Torino: Il Mulino, 1997.

DARNTON, Robert. Boemia literária e revolução: o submundo das letras no Antigo Regime. São Paulo: Companhia das Letras, 1987.

DEKKER, Rudolf. Childhood, memory and autobiography in Holland. From the Golden Age to Romanticism. Basingstoke, Palgrave Macmilan, 1999. DOI: https://doi.org/10.1007/978-1349-62377-8.

DEL PRIORE, Mary. História da criança no Brasil. São Paulo: Contexto, 1991.

DEL PRIORE, Mary. História das crianças no Brasil. São Paulo: Contexto, 1998.

FARIA FILHO, Luciano Mendes de; ARAÚJO, Vânia. (orgs.). História da educação e assistência à infância no Brasil. Vitória: EDUFES, 2011.

FASS, Paula (org.) Encyclopedia of Children and Childhood: In History and Society. 2003. Disponível em: http://www.faqs.org/childhood/A-Ar/index.html Acesso em 17/11/2017.

FEBVRE, Lucien. Combates pela História. Lisboa: Presença, 1989.

FERRARI, Monica et. al. Autografie dell'etá minore: lettere di tre dinastie italiane tra Quattrocento e Cinquecento. Roma: Viella, 2016.

FREITAS, Anamaria Gonçalves Bueno de; CUNHA, Amália da. Dimensões da condição feminina no final do século 19, nas páginas do diário "Minha vida de menina" (1893-1895). Horizontes. Bragança Paulista, v. 19, jan.-dez. 2001, p. 29-42.

FREYRE, Gilberto. Ordem e Progresso. São Paulo: Global, 2010.

GALVÃO, Ana Maria de Oliveira. A palmatória era sua vara de condão: práticas escolares na Paraíba. In: FARIA FILHO, Luciano Mendes de (org.) Modos de ler, formas de escrever: estudos de história da leitura e da escrita no Brasil. Belo Horizonte: Autêntica, 1998, p. 117-142. 
GIALLONGO, Ângela. Prefazzione all'edizione italiana. In: DELGADO, Buenaventura. Storia dell'Infanzia. Bari: Dédalo, 2002, p. 7-18.

GOUVÊA, Maria Cristina Soares de. A escrita da História da Infância: periodização e fontes. In: GOUVÊA, Maria Cristina Soares de; SARMENTO, Manuel Jacinto. (orgs.) Estudos da Infância. Petrópolis: Vozes, 2009, p. 97-118.

HEYWOOD, Colin. Uma história da infância: da Idade Média à época contemporânea no Ocidente. Porto Alegre: Artes Médicas, 2004.

JÍMENEZ; Pablo Rodríguez; MANNARELI, Maria Emma (coords). Historia de la infancia en America Latina. Bogotá: Universidad Externado de Colômbia, 2007.

JULIA, Dominique. A cultura escolar como objeto histórico. Revista Brasileira de História da Educação. Campinas, n. 1, jan.-jun. 2001, p. 9-43.

LAGE, Ana Cristina Pereira. A memória educacional de um campanhense. Minas Gerais, século 19. Congresso Brasileiro de História da Educação, 4. Anais... Goiânia: Universidade Federal de Goiás, 2006.

LEJEUNE, Philippe. "Le journal de jeune fille" nella Francia del Ottocento. In: BECCHI, Egle; ANTONELLI, Quinto. (a cura di) Scritture Bambine. Roma-Bari: Laterza, 1995, p. 25-42.

MARCÍLIO, Maria Luiza. História social da criança abandonada. São Paulo: Hucitec, 1998.

MARIANO, Nayana Rodrigues Cordeiro. Um memorialista e o seu tempo: Coriolano de Medeiros e a instrução na Parahyba oitocentista. Congresso Brasileiro de História da Educação, 9. Anais... João Pessoa: Universidade Federal da Paraíba, 2017.

MEDA, Juri; MONTINO, Davide; SANI, Roberto (Ed.) School exercise books. A complex source for a History of the Approach to Schooling and Education in the 19th and 20h Centuries. 2 Vol. Firenze: Edizioni Polistampa, 2010.

OLIVEIRA, Amurabi. A meninice no pensamento de Gilberto Freyre. Política e Trabalho. N. 43, jul.-dez. 2015, p. 203-218.

PERES, Eliane Teresinha. Viagens e passeios familiares e escolares registrados em cadernos de alunos (1957-2015). Revista Brasileira de Pesquisa (Auto) Biográfica. Salvador, v. 02, n. 5, mai.-ago. 2017, p. 290-309. DOI: https://doi.org/10.31892/rbpab2525426X.2017.v02.n05.p290-309.

PERES, Eliane Teresinha; BORGES, Francine. Relações entre história e literatura: a obra de Cora Coralina e as questões do ensino e dos processos de escolarização no final do século $19 \mathrm{e}$ início do século 20. Revista Brasileira de História da Educação. Maringá, v. 15, n. 2, mai.- ago 2015, p.23-53. DOI: https://doi.org/10.4025/rbhe.v15i2.676.

POLLOCK, Linda A. Los niños olvidados: relaciones entre padres e hijos de 1500 a 1900. México: Fondo de Cultura Económica, 2004. 
RAFFAINI, Patrícia Tavares. Cartas de crianças: reflexões sobre a leitura nas décadas de 1930 e 1940. Angelus Novus. São Paulo, n. 10, 2015, p. 129-158.

RIZZINI, Irma. Crianças desvalidas, indígenas e negras: cenas da Colônia, do Império e da República. Rio de Janeiro: EDUSU, 2000.

SANTOS, Luciana; CUNHA, Maria Teresa Santos. Infâncias por escrito: cartas de escolares em um suplemento infantil catarinense (1972-1987). Revista de História e Historiografia da Educação. Curitiba, v.1, n.3, set.-dez. 2017, p.323-354. DOI: https://doi.org/10.5380/rhhe.v1i3.52752.

SOSENSKI, Susana; ALBARRÁN, Elena Jackson (coords.) Nuevas miradas a la historia de la infancia en América Latina: entre prácticas e representaciones. México: UNAM, 2012.

SOUZA, Gizele de. Educar na Infância: perspectivas histórico-sociais. São Paulo: Contexto, 2010. STEARNS, Peter. Infância. São Paulo: Contexto, 2006.

VALDEZ, Diane. A infância escolar nas lembranças de Cora Coralina. Congresso Brasileiro de História da Educação, 6. Anais. Vitória: Universidade Federal do Espírito Santo, 2011, v.1, p.1-15.

VIÑAO, Antonio. A modo de prólogo, refugios del yo, refugios de otros. In: MIGNOT, Ana Cristina Venâncio; BASTOS, Maria Helena Câmara; CUNHA, Maria Teresa Santos (org.) Refúgios do eu: educação, história, escrita autobiográfica. Florianópolis: Mulheres, 2000, p. 9-15.

WARDE, Mirian Jorge. Repensando os estudos sociais de história da infância no Brasil. Perspectiva. Florianópolis, v. 25, n. 1, jan.-jun. 2007, p. 21-39. 